\title{
Morfologia endodôntica de caninos e pré-molares inferiores
}

Nicolau F. Milano* Carlos A. G. da Silva** Angelo O. Manfro Jr. **

\begin{abstract}
RESUMO
Os autores estudaram radiografias "in vivo" e de dentes extraídos de caninos, primeiros e segundos pré-molares inferiores, para estabelecer-se o número de canais bem como a localizaçāo da bifurcação, quando da existência de dois canais.

Os resultados mostraram $9,1 \%$ de caninos, $30,9 \%$ de primeiros prés e $12,3 \%$ de segundos prés inferiores com dois canais.
\end{abstract}

\section{DESCRITORES}

\section{ENDODONTIA • TRATAMENTO DE CANAIS • ANATOMIA}

\section{INTRODUÇÃO E PROPOSIÇÃOO}

Considerando-se que o trabalho endodôntico é feito sem ser visto, a não ser pela radiografia, que só nos mostra duas dimensōes, torna-se fundamental o conhecimento detalhado da morfologia endodôntica, especialmente nas situaçōes atípicas.

Esse é o propósito do presente trabalho que se propōe a uma avaliação de frequência da morfologia endodóntica dos caninos e dos pré-molares $\left(1^{\circ}\right.$ e $\left.2^{\circ}\right)$ inferiores.

\section{REVISÃO BIBLIOGRÁFICA}

A revisāo da literatura deste trabalho abrange 15 autores; contudo, destes, apenas 06 mostraram dados originais, enquanto que outros 09 citaram trabalhos publicados de outrem.

Cabe salientar também que os anatomistas, como Della Serra (3), Picosse (10) e Sicher (13) ocuparam-se apenas da morfologia radicular (externa) e não da endodôntica (interna).

Passando à exposiçảo, agruparemos as citaçōes que abordam os caninos, os primeiros pré-molares e os segundos pré-molares inferiores.

\section{CANINOS INFERIORES}

Hess (4) apresenta cifras bastante discrepantes dos demais autores, afirmando encontrar 2 canais em $40 \%$ dos casos.

De Deus (2) cita $11,8 \%$ de caninos inferiores com 2 canais, enquanto Pucci (12) refere apenas $2,3 \%$.

Vertucci (15) em análise histológica concluiu que em apenas $6 \%$ dos casos haveria 2 canais.

Kuttler (7) menciona resultados semeIhantes ao apontar a cifra de $5 \%$ com 2 canais.

Imura e Zuolo (5) relatam a frequência de $10 \%$ de peças com 2 canais.

$1^{\circ}$ PRÉ-MOLAR INFERIOR

Hess (4) novamente surpreende com seus números ao apontar apenas $3 \%$ de peças com 2 canais.

Zillich e Dowson (16) estudaram radiograficamente 1393 primeiros pré-molares inferiores extraídos, achando $22,7 \%$ de casos com 2 canais e $0,4 \%$ com 3 canais.

Kuttler (7) informa que esse grupo de dentes apresenta-se com 2 canais em $24,9 \%$ e com 3 canais em $0,9 \%$.

Vertucci (15) mostra resultados semeIhantes a Kuttler com as cifras de $25,5 \%$ com 2 canais e $0,5 \%$ com 3 canais, em casuística de 100 casos.

De Deus (2) estudando 102 dentes encontrou 2 canais em $31,3 \%$ das peças e 3 canais em $2,1 \%$.

$2^{\circ}$ PRÉ-MOLAR INFERIOR

Hess (4) refere $10 \%$ de casos com 2 canais.
De Deus (2) em amostra de 75 dentes, observou $10,7 \%$ de casos com 2 canais. Kuttler (7) refere $1,2 \%$ de peças com 2 canais. Zillich e Dowson (16) estudando 938 peças classificaram $11,7 \%$ com 2 canais e $0,4 \%$ com 3 canais. Pucci e Reig (12) citam apenas $1,4 \%$ de dentes com 2 canais. Vertucci (15) menciona que em somente $2,5 \%$ de casos são encontrados 2 canais.

\section{MATERIAL E MÉTODO DE TRABALHO}

Esses grupos de dentes foram avaliados em sua morfologia endodôntica por dois métodos, ambos utilizando a radiografia. Um determinado número de peças foi examinado em radiografias clínicas (in vivo) e outro, constituído de dentes extradidos, foi também avaliado pela radiografia (in vitro).

\section{RESULTADOS}

Os resultados dos exames foram agrupados e tabulados, também por grupos de dentes e método de exame, se in vitro ou in vivo. Com isso foi possível fazer uma comparação entre a eficiência dos

\footnotetext{
* Professor Titular de Endodontia da F.O./UFRGS

** Interno da Disciplina de Endodontia da F.O./UFRGS
}

R. Fac. Odontol.
Porto Alegre
V. 32

N. 1 p.25-26 JULHO 
métodos utilizados.

A análise permitiu serem selecionados dentes com 1 ou 2 canais, com a bifurcaçāo nos terços cervical, médio ou apical, conforme mostram as tabelas a seguir. a. Caninos inferiores $-9,0 \%$

b. Primeiros pré-molares $31,9 \%$

c. Segundos pré-molares inferiores $12,3 \%$
DENTES RADIOGRAFADOS "IN VIVO"

\begin{tabular}{|c|c|c|c|c|c|c|c|c|c|c|c|}
\hline & \multicolumn{2}{|c|}{1 CANAL } & \multicolumn{8}{|c|}{2 CANAIS } & \multirow{3}{*}{$\begin{array}{c}\text { N: } \\
\text { TOTAL } \\
\text { DE } \\
\text { DENTES }\end{array}$} \\
\hline & \multirow{2}{*}{\begin{tabular}{c|}
$N:$ \\
$D E$ \\
$D E$ \\
DENTES
\end{tabular}} & \multirow{2}{*}{$\%$} & \multicolumn{2}{|c|}{ 1/3 APICAL } & \multicolumn{2}{|c|}{ 1/3 MÉDIO } & \multicolumn{2}{|c|}{ 1/3 CERVICAL } & \multirow{2}{*}{ № } & \multirow{2}{*}{$\%$} & \\
\hline & & & DENTES & $\%$ & DENTES & $\%$ & DENTES & $\%$ & & & \\
\hline Can. & 68 & 93,15 & - & - & - & - & 5 & 6,84 & 5 & 6,84 & 73 \\
\hline 1! PM & 123 & 80,6 & 1 & 3,2 & 15 & 46,8 & 16 & 50,0 & 32 & 19,4 & 155 \\
\hline 2: PM & 183 & 92,89 & - & - & 3 & 21,42 & 11 & 78,57 & 14 & 7,10 & 197 \\
\hline
\end{tabular}

DENTES RADIOGRAFADOS "IN VITRO"

\begin{tabular}{|c|c|c|c|c|c|c|c|c|c|c|c|}
\hline & \multicolumn{2}{|c|}{1 CANAL } & \multicolumn{8}{|c|}{2 CANAIS } & \multirow{3}{*}{$\begin{array}{c}\mathrm{N}: \\
\text { TOTAL } \\
\text { DE } \\
\text { DENTES }\end{array}$} \\
\hline & \multirow{2}{*}{$\begin{array}{c}N= \\
\text { Ne } \\
\text { DE } \\
\text { DENTES }\end{array}$} & \multirow{2}{*}{$\%$} & \multicolumn{2}{|c|}{ 1/3 APICAL } & \multicolumn{2}{|c|}{ 1/3 MÉDIO } & \multicolumn{2}{|c|}{ 1/3 CERVICAL } & \multirow{2}{*}{ № } & \multirow{2}{*}{$\%$} & \\
\hline & & & DENTES & $\%$ & DENTES & $\%$ & DENTES & $\%$ & & & \\
\hline Can. & 30 & 90,9 & - & - & 1 & 33,3 & 2 & 66,6 & 3 & 9,1 & 33 \\
\hline $1 \stackrel{P M}{ }$ & 32 & 68,1 & 2 & 13,2 & 9 & 60,0 & 4 & 26,6 & 15 & 31,9 & 47 \\
\hline $2: P M$ & 50 & 87,7 & 4 & 57,1 & 2 & 28,6 & 1 & 14,3 & 7 & 12,3 & 57 \\
\hline
\end{tabular}

\section{DISCUSSÃO}

Ficou manifesto que a avaliaçāo da topografia endodôntica é mais fiel em radiografias de dentes extraídos (in vitro), todavia, por razōes óbvias é mais difícil conseguir-se uma amostra tão expressiva quanto a conseguida de radiografias clínicas (in vivo).

A semelhança entre os dados encontrados na literatura e os do presente trabalho $e$ apenas relativa. $O$ fato deve ser atribuído a diferentes métodos de trabaIho.

Entendemos importante para o endodontista o conhecimento detalhado da morfologia atípica dos dentes estudados na medida em que a frequência das anomalias mostrou-se significante.

Outrossim cabe ressaltar que esses grupos de dentes, em sua apresentaçāo normal, sảo extremamente simples em seu preparo, enquanto que, quando anômalos mostram-se extremamente complexos e de dificílima abordagem endodôntica. Daí a propriedade do comentário de Cohen acerca da endodontia nesses dentes. Assim se expressa o autor: "Quando se pergunta a um endodontista experimentado, qual o dente que Ihe causou maiores problemas, usualmente ele dará um suspiro e a resposta mastigada - aquele miserável $1^{\circ}$ pré-molar inferior.

\section{CONCLUSÕES}

Analisando radiografias de dentes extraídos (in vitro) encontramos as seguintes cifras de dentes com dois canais:

\section{REFERÊNCIAS \\ BIBLIOGRÁFICAS}

1. COHEN, S. \& BURNS, R.C. Caminhos da polpa. Trad. S. Bevilacqua, 2. ed. Rio de Janeiro, Guanabara Koogan, 1982. p. 91.

2. DE DEUS, Q.D. Endodontia. 4. ed. Rio de Janeiro, Medsi, 1986. p. 47.

3. DELLA SERRA, O.; FERREIRA, F.V. Anatomia dental. 2. ed. Sāo Paulo: Artes Médicas, 1976. p. 99.

4. HESS, W. apud ARAUJO, M.J. \& ARAUJO, M.C. Anatomia da cavidade pulpar. Rev. Bras. Odontol., 26 (147), p. 338-68, maio/jun, 1967.

5. IMURA, M. \& ZUOLO, M.L. Procedimentos clínicos em endodontia. Sāo Paulo, Pancast, 1988. p. 86.

6. INGLE, J. \& BEVERIDGE, E.E. Endodontia. Trad. J.C.B. Telles. 2. ed. Rio de Janeiro, Interamericana, 1979. p. 123.

7. KUTTLER, Y. Endodontia practica. Mexico, Alpha, 1961. p. 28.

8. LASALA, A. Endodoncia. Caracas: Cromotip, 1971. p. 12.

9. LEONARDO, M.R.; LEAL, J.M.; SIMŌES, A.P. Endodontia. São Paulo: Panamericana, 1982. p. 136.

10. PICOSSE, M. Anatomia dentária. 4. ed. Sāo Paulo, Sarvier, 1987. p. 37.

11. PRECIADO, V.Z. Manual de Endodoncia. Mexico, Cuelar, 1975. p. 82.

12. PUCCI, F.M. \& REIG, R. Conductos radiculares. Montevideo: Médico Cirurgica, 1944. p. 218.

13. SICHER, A. Anatomia bucal. 6. ed. Rio de Janeiro. Guanabara Koogan, 1977. p. 219.

14. VALLS, L.A. Endodoncia. Cuba, Instituto Cubano do Livro, 1977. p. 56.

15. VERTUCCI, F. Root canal anathomy of the mandibular anterior teeth. J. Am. Dent. Assoc., 89. p. 369-71, 1974.

16. ZILLICH, R. \& DAWSON, J. Root canal morphology of mandibular first and second premolars. Oral Surg. Oral Med. Oral Pathol. 36, p. 738-44, 1973.

\section{R. Fac. Odontol.}

Porto Alegre

V. 32

N. 1

p.26-26

JULHO 